${ }^{1}$ Laboratory of Applied Materials Chemistry, University of Namur (Unamur), 61 rue de Bruxelles, B5000, Namur, Belgium (*armela.aprile@unamur.be "mireia.buaki-sogo@unamur.be)

${ }^{2}$ Department of Biological Chemical and Pharmaceutical Sciences and Techologies (STEBICEF), Università di Palermo, Viale delle Scienze s/n, Ed. 17, I-90128, Palermo, Italy ("michelangelo.gruttadauria@unipa.it)

I. INTRODUCTION: Development of green processes based on chemical fixation of carbon dioxide has attracted the attention of the scientific community due to the possibility to transform a waste, such as $\mathrm{CO}_{2}$, into useful products. Cyclic carbonates, synthetized through the reaction between $\mathrm{CO}_{2}$ and epoxides, are interesting compounds that can be used for several applications, such as electrolytes for lithium batteries and polar aprotic solvents. Due to its thermodynamic and kinetic stability, carbon dioxide conversion is difficult to achieve and an efficient catalyst is required. ${ }^{1}$ Various homogeneous and heterogeneous catalysts have been proposed for this reaction. Recently, ionic liquids have emerged as a novel class of organocatalysts. In particular, imidazolium-based ionic liquids have become very attractive since they are one of the most efficient catalysts for $\mathrm{CO}_{2}$ conversion to produce cyclic carbonate from epoxydes. ${ }^{2}$ Here the synthesis and applications of a novel class of imidazolium catalyst based on the functionalization of Polyehedral Oligomeric Silsesquioxane (POSS) is presented. ${ }^{3}$

AIM: In the present work we present a silsesquioxane based nanostructure functionalized with imidazolium chloride as efficient catalyst for the chemical fixation of carbon dioxide.

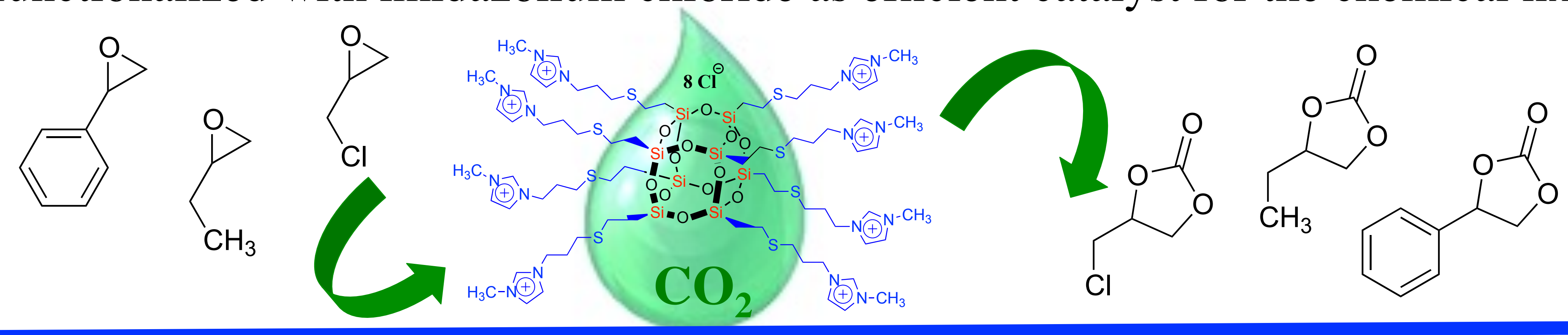

\section{SYNTHETIC STRATEGY AND CHARACTERISATION}

Procedure: Synthesis of POSS-Cl and POSS-Imi (1 and 2)

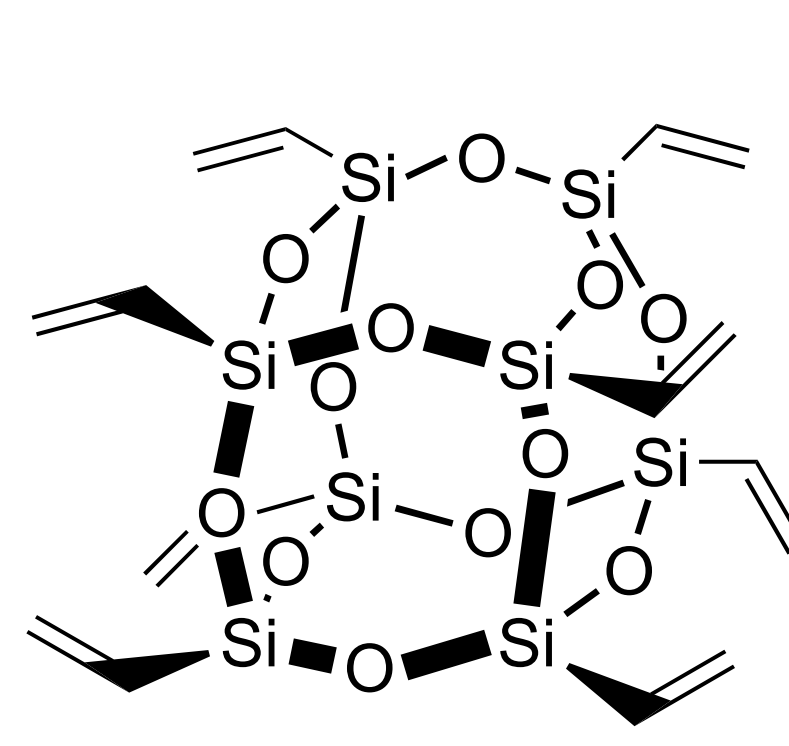
$\underset{\underset{(8.8 \text { eq. })}{\text { tibn, } 60^{\circ} \mathrm{C}, 13 \mathrm{~h}}}{\mathrm{HS}}$
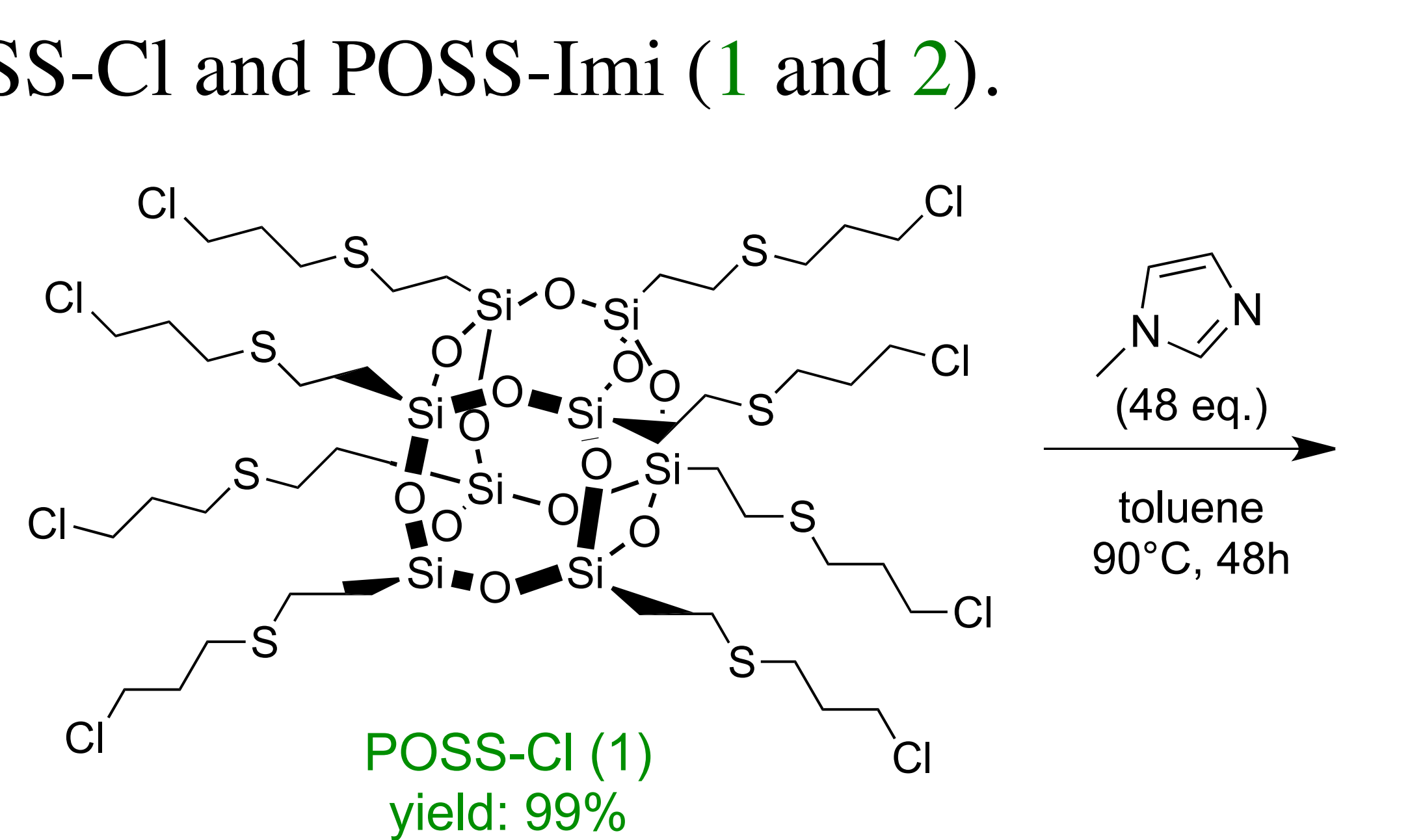

${ }^{1}$ H-NMR (400MHz)

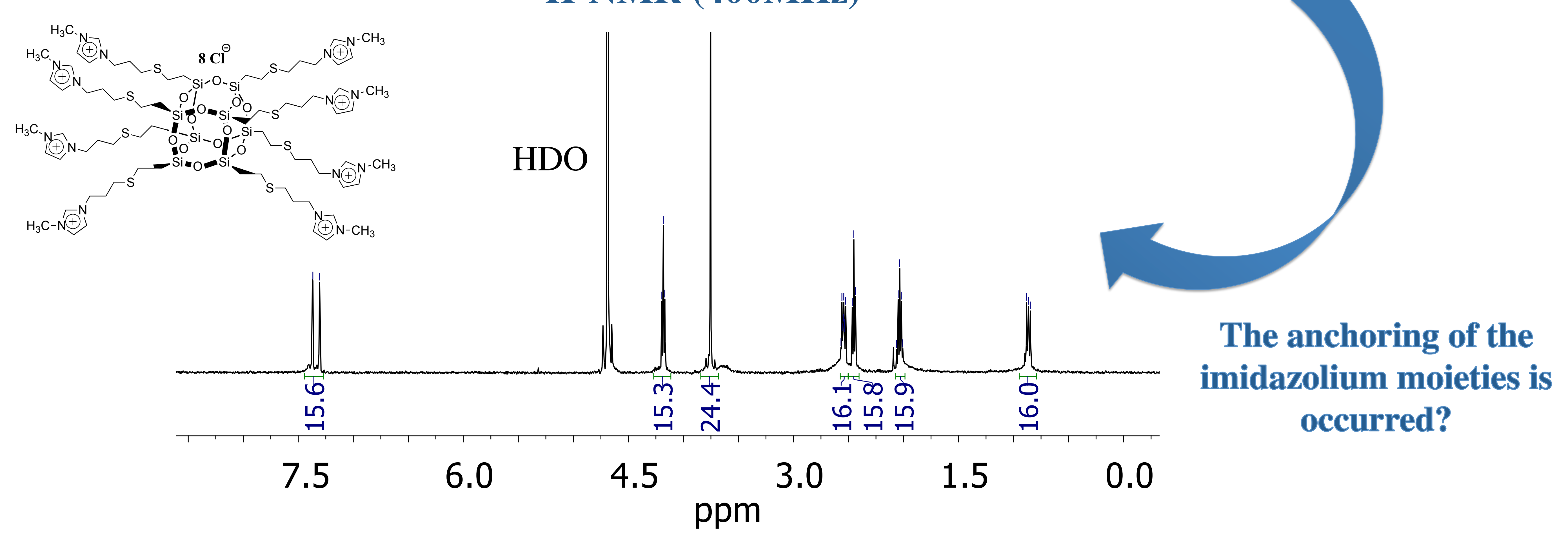

${ }^{29} \mathrm{Si}-\mathrm{NMR}(500 \mathrm{MHz})$

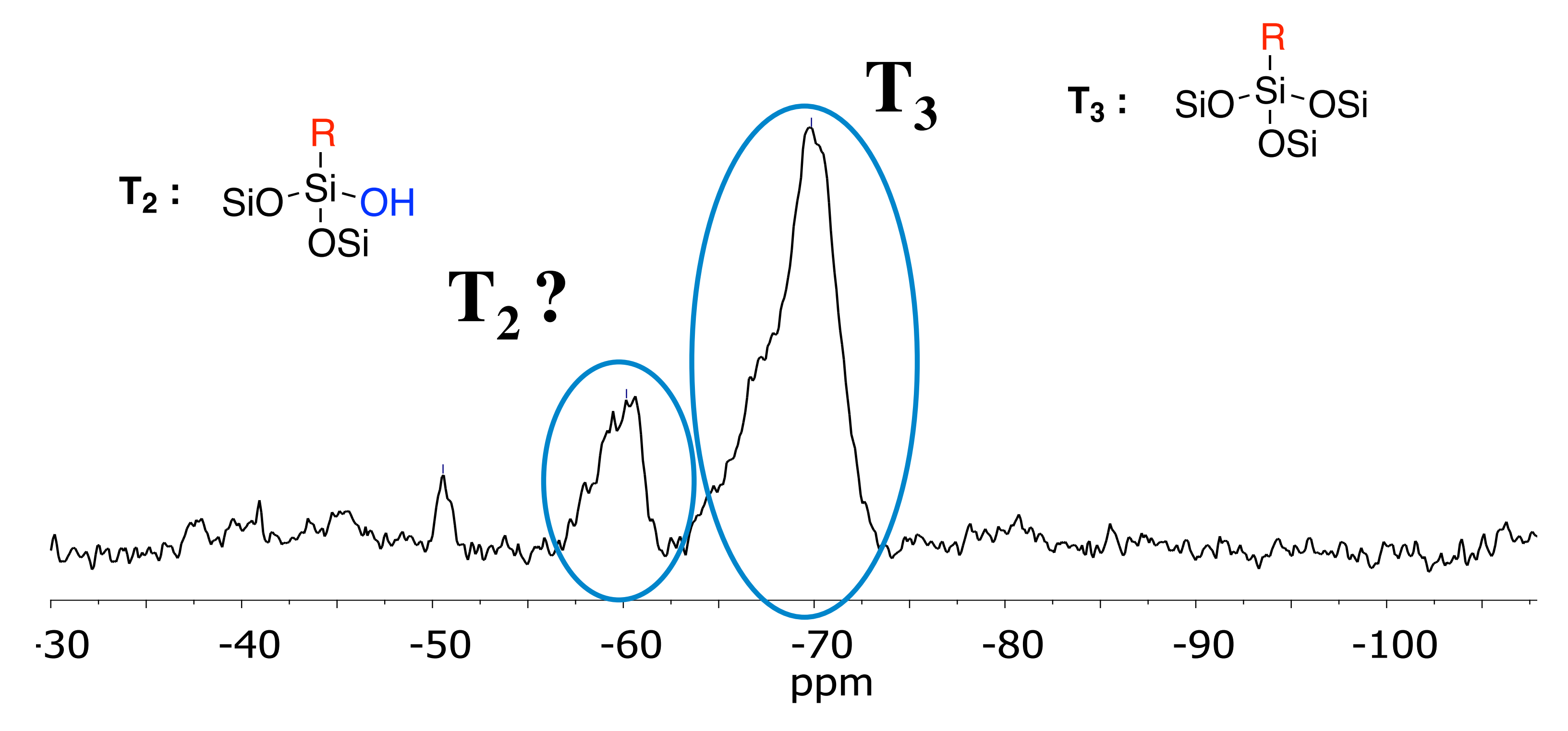

Imidazolium based POSS is stable?
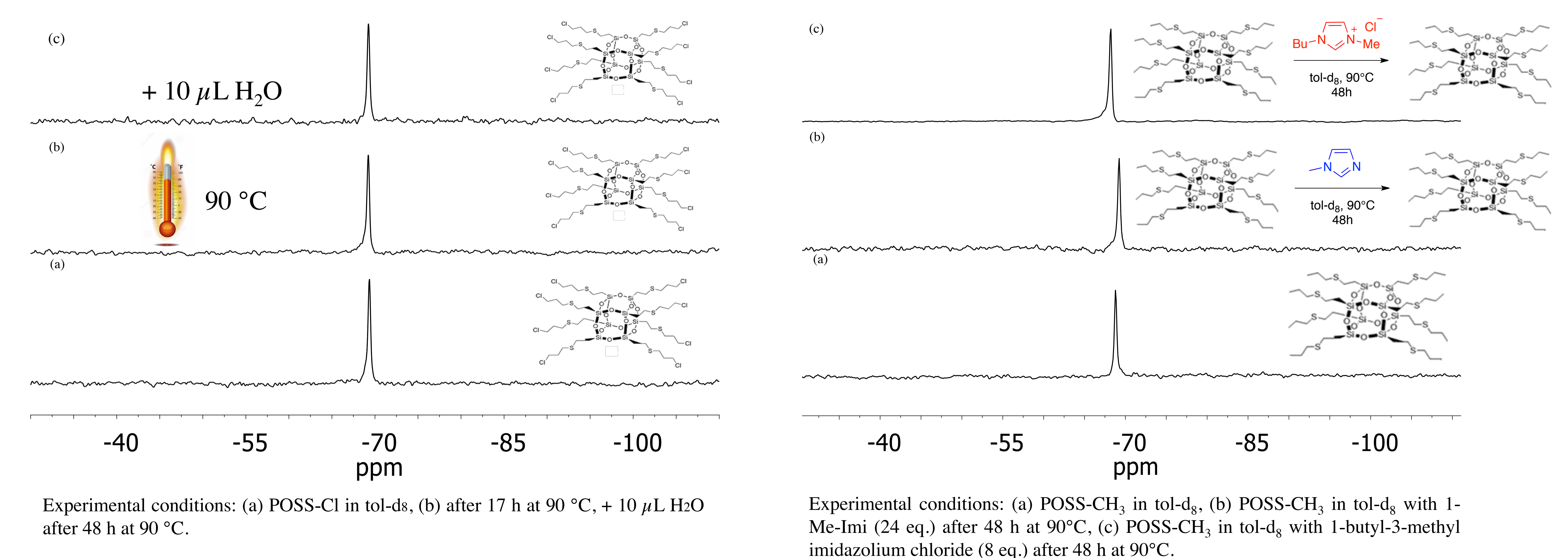

\title{
III. CATALYTIC TESTS
}

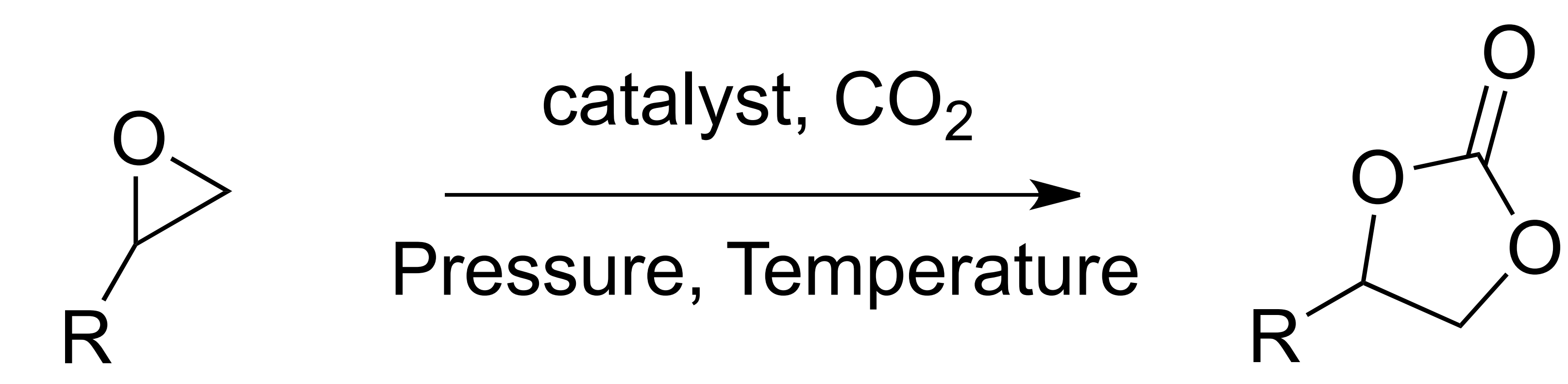

Procedure: Investigation of reaction conditions with POSS-Imi.

(a) In function of the pressure

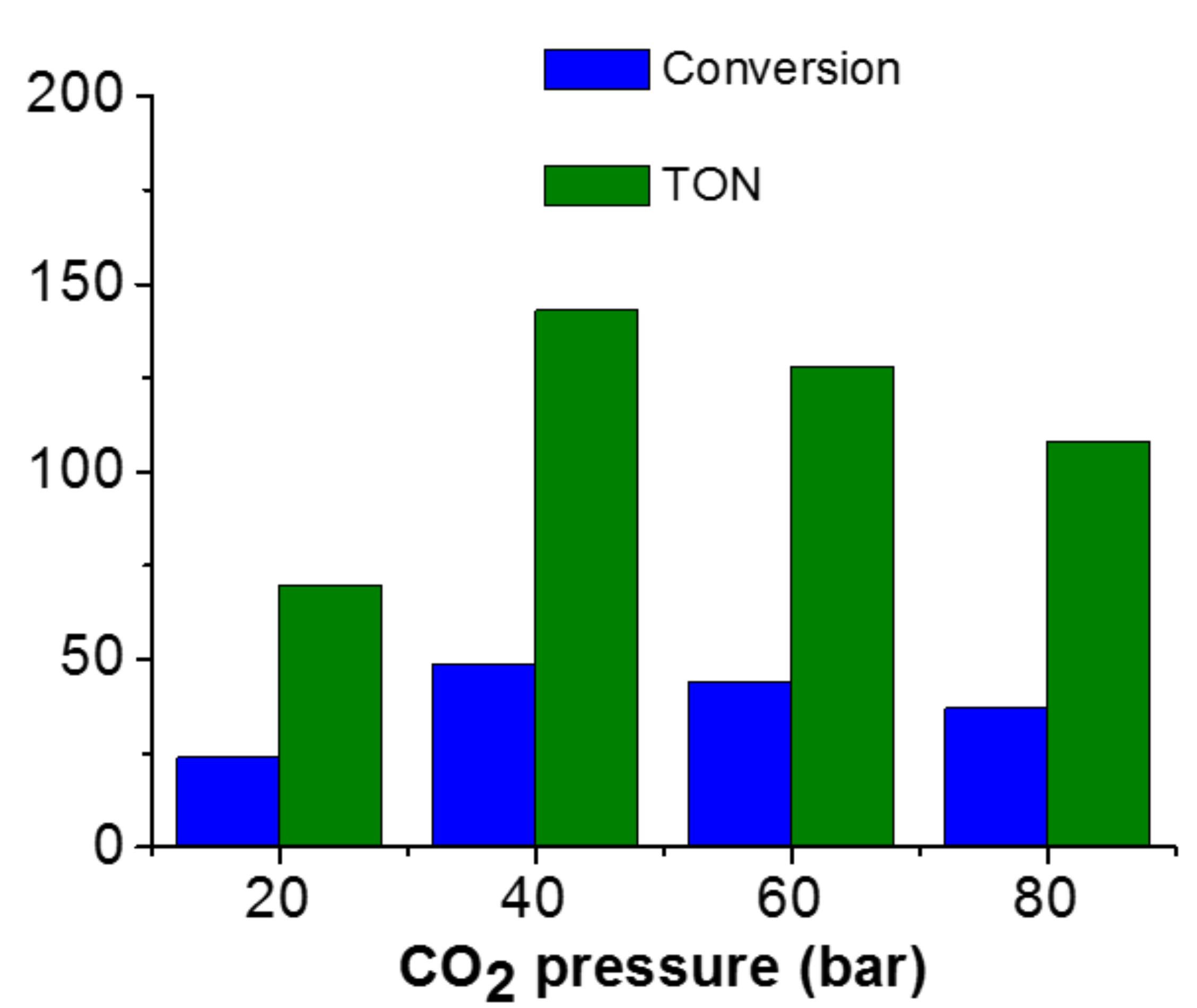

(b) In function of the amount of the catalyst

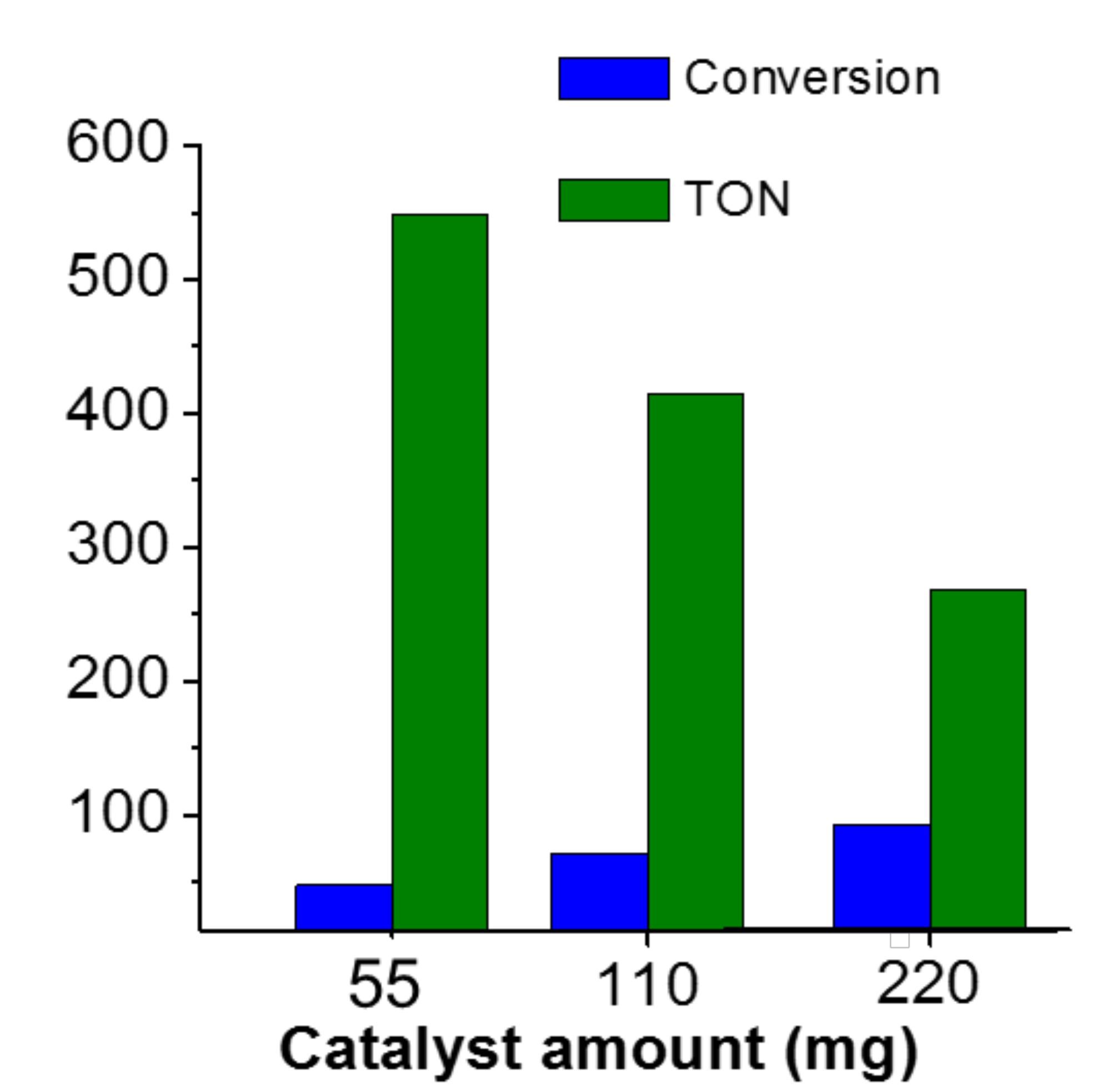

Conversion and TON $\left(\mathrm{n}_{\text {converted }} / \mathrm{n}_{\text {active sites }}\right)$ of the reaction varying the $\mathrm{CO}_{2}$ pressure at $125^{\circ} \mathrm{C}$, with $220 \mathrm{mg}$ of catalyst in $\mathrm{H}_{2} \mathrm{O}$ (a) and the catalyst amount at 40 bar, $150{ }^{\circ} \mathrm{C}$, in $\mathrm{H}_{2} \mathrm{O}$ (b). 